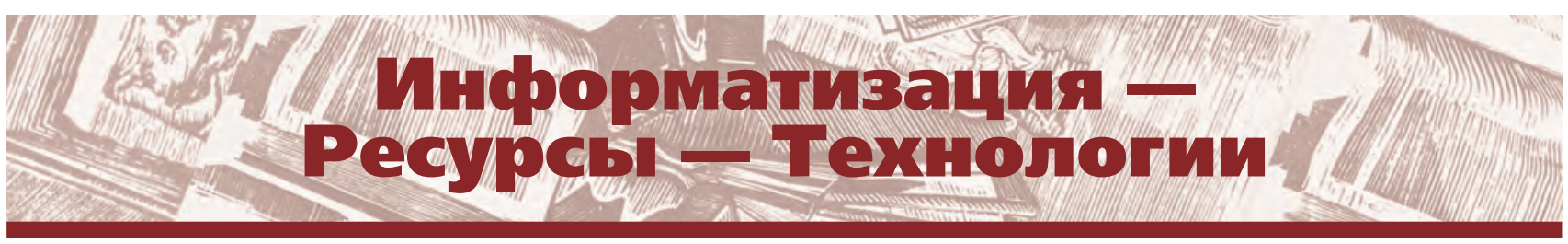

УДК 024.6 (470+571)

ББК 78.378

DOI 10.25281/0869-608X-2017-66-4-387-395

И.Ю. Красильникова

Компоненты развития

национальной системы

межбиблиотечного абонемента

и доставки документов

для поддержки научных коммуникаций в России

Реферат. В современных условиях расширения электронной среды в процессе обслуживания по межбиблиотечному абонементу (МБА) и доставке документов (ДД) возникает ряд проблем, от успешного решения которых зависит развитие взаимоиспользования информационно-библиотечных ресурсов, содействующее научным коммуникациям. В целях определения ориентиров прогрессирования МБА и ДД выявлены компоненты, которые могут активизировать деятельность. К ним относятся: полнота комплектования фондов; обновление законодательных документов; технологические подходы с применением автоматизации и информатизации; организационно-технологические вопросы (регламентирующие документы, оперативность выполнения заказов, предотвращение отказов, оптимизация платных услуг, доступность статистических показателей работы).

Рассмотрены основные пути, способствующие адаптации подразделений МБА и ДД к формирующимся условиям в электронной среде и последующему обновлению. Обращается внимание на необходимость установления взаимодействия подразделений МБА и ДД с Национальной электронной библиотекой, соблюдения юридических норм при оцифровке документов, доступности электронных документов пользователям МБА и ДД. Предлагается разработать новый ГОСТ по МБА и ДД, закрепить единые нормативные сроки обработки заказов, контролировать оперативность их выполнения, выработать предупредительные меры, направленные на устранение превышения сроков. Оперативность ДД диктует необходимость создания унифицированного перечня формулировок отказов, возобновления порядка перенаправления отказов по причине «единственный экземпляр не выдается по МБА» от одного исполнителя к другому. Взимание платы за отказы следует признать неоправданным, так как заказчик не получил требуемый документ. Сбор и доступность статистических показателей деятельности МБА и ДД позволит получать и изучать количественные и качественные характеристики происходящего. Предложенные акции направлены на оптимизацию МБА и ДД России.

Ключевые слова: автоматизация, авторское право, доставка документов, комплектование фондов, межбиблиотечный абонемент, МБА, обязательный экземпляр, оперативность, платные услуги, регламентирующая документация, стандарты, статистические показатели, электронная библиотека.

Ирина Юрьевна
Красильникова,
Государственная публичная
научно-техническая
библиотека Сибирского
отделения Российской
академии наук,
старший научный
струдник
Восход ул., д. 15,
Новосибирск, 630200,
Россия
кандидат
педагогических наук
E-mail:
krasilnikova@ @spsl.nsc.ru


Для цитирования: Красильникова И.Ю. Компоненты развития национальной системы межбиблиотечного абонемента и доставки документов для поддержки научных коммуникаций в России // Библиотековедение. 2017. T. 66, № 4. С. 387-395. DOI: 10.25281/0869-608X-2017-66-4-387-395.

$\mathrm{M}$ ежбиблиотечный абонемент (МБА) и доставка документов (ДД), как и другие направления библиотечной деятельности, трансформируются в условиях сокращения финансирования библиотек, уменьшения числа печатных изданий, соблюдения правовых норм и распространения электронной информации и документов [1]. Пользователь, оформляя заказ по МБА и ДД, надеется на оперативный и положительный ответ. Сегодня этому способствуют различные информационные источники и способы доставки документов. В целях совершенствования МБА и ДД и расширения научных коммуникаций необходимо выработать стратегию развития инноваций в предоставлении документов [2]. Рассмотрим компоненты, которые позволят активизировать эту деятельность:

- полнота комплектования фондов;

- обновление законодательных документов (системы обязательного экземпляра и авторского права, Национальная электронная библиотека);

- технологические подходы с применением автоматизации и информатизации;

- организационно-технологические вопросы (регламентирующие документы, оперативность выполнения заказов, предотвращение отказов, оптимизация платных услуг, сбор и доступность статистических показателей работы).

\section{Полнота комплектования фондов}

Государственная публичная научно-техническая библиотека Сибирского отделения Российской академии наук (ГПНТБ СО РАН) проводит исследования по актуальным вопросам библиотековедения, библиографоведения, книговедения. Особое место занимает изучение проблематики комплектования фондов, от которых зависит вся библиотечная работа, в том числе обслуживание по МБА и ДД.

Исследовав поток научных изданий за 20092012 гг., представители отделов комплектования выявили, что произошло снижение общего объема поступлений научной, переводной, учебной литературы для вузов, а также по названиям [3]. Половина изданий для высшей школы не имеет статуса рыночного ассортимента, реализуется внутри учебных заведений и почти недоступна для российских библиотек. Наблюдается возрастание доли малотиражных изданий (30-45\% ) [3, c. 13], которых немного представлено на книжном рынке и в составе обязательного экземпляра (ОЭ) Российской книжной палаты (РКП).

После всплеска в 2013 г. темпы обновления фондов ГПНТБ СО РАН отечественными издани- ями значительно снизились. Влияние оказали следующие факторы: прекращение централизованного комплектования библиотек научно-исследовательских учреждений СО РАН в результате реформы РАН; секвестирование бюджетного финансирования; сокращение подписного репертуара отечественных и иностранных журналов. Это отрицательно сказалось на показателях посещаемости и книговыдачи, в том числе по МБА и ДД. О схожих проблемах в комплектовании фондов и важности получения документов по МБА и ДД писали представители Библиотеки по естественным наукам (БЕН) РАН [4, с. 14-15].

Вместе с тем проявляются и положительные тенденции. Так, все более заметным сегментом российского книжного рынка становится цифровой контент книг. Активно предлагают свои ресурсы электронные библиотечные системы (ЭБС), предоставляющие онлайн-доступ к защищенным файлам тематических комплектов [3, с. 16].

Исследователи ГПНТБ СО РАН отмечают, что наблюдаются перемены в прежней системе научно-технической информации [3], ресурсы которой запрашиваются отечественными и зарубежными пользователями системы МБА и ДД.

\section{Обновление законодательных документов}

Систелиа обязательного экзелпляра. С 2012 г. острой темой в профессиональных обсуждениях издателей и библиотекарей стало реформирование закона «Об обязательном экземпляре документов» [5] с целью введения понятия «Электронная копия печатного издания». В 2013 г. исполнилось 230 лет появлению ОЭ в России на законодательном уровне, что позволяло регулярно и полно комплектовать фонды крупнейших библиотек страны. Между тем отмечалась заметная степень нарушения этого закона, которая по разным оценкам составляла от 20 до $30 \%$ [6, с. $22-23]$. Это обусловливало рост числа отказов по МБА и ДД.

Некоторые разработчики закона «Об обязательном экземпляре документов» рассматривали электронную копию печатного издания как основной источник комплектования Национальной электронной библиотеки (НЭБ). Были предложения отнести ее к источнику долговременного национального культурного наследия в архиве печати - РКП, при этом издатель (правообладатель) может обратиться в национальный архив с запросом об использовании электронной копии, переданной на долговременное хранение. В то же время две ведущие национальные библио- 
теки Российской Федерации - Российская государственная библиотека (РГБ) и Российская национальная библиотека (РНБ) последовательно выступают за широкий доступ читателей к обязательным экземплярам печатных изданий в электронной форме при неуклонном соблюдении всех норм авторского права, закрепленных в части четвертой Гражданского кодекса Российской Федерации.

Систела авторского права. В соответствии с Федеральным законом № 35-ФЗ «О внесении изменений в части первую, вторую и четвертую Гражданского кодекса Российской Федерации и иные законодательные акты Российской Федерации» [8], вступившим в силу в 2014 г., общедоступные библиотеки вправе создавать единичные копии документов, в том числе в электронной форме, в целях обеспечения сохранности и доступности для пользователей:

- ветхих, изношенных, испорченных, дефектных документов;

- единичных и (или) редких документов, рукописей, выдача которых пользователям может привести к их утрате, порче или уничтожению;

- документов, записанных на машиночитаемых носителях, для пользования которыми отсутствуют необходимые средства;

- документов, имеющих исключительно научное и образовательное значение, при условии, что они не переиздавались свыше десяти лет со дня выхода в свет их последнего издания на территории России;

- утраченных или испорченных документов (а также предоставлять их другим общедоступным библиотекам, утратившим их по каким-либо причинам).

Копированию подлежат отдельные статьи и малообъемные произведения, правомерно опубликованные в сборниках, газетах и других периодических печатных изданиях, короткие отрывки из иных правомерно опубликованных письменных произведений (с иллюстрациями или без иллюстраций). Библиотеки, получающие экземпляры диссертаций в соответствии с законом об ОЭ документов, вправе создавать единичные копии таких диссертаций, в том числе в электронной форме, в целях обеспечения их сохранности и доступности для пользователей [8]. Библиографические ссылки на использованные отрывки должны быть обязательны.

Изучением проблем авторского права применительно к МБА и ДД занимались специалисты ГПНТБ СО РАН $[9 ; 10]$. Рассматривались вопросы соблюдения авторского права и возможность выполнения технологии электронной доставки документов (ЭДД), которая внедрена в крупных библиотеках России с 1994 г., т. е. до вступления в силу части четвертой Гражданского кодекса Российской Федерации (2008). Применение информационных технологий в МБА и ДД придало новый импульс развитию межбиблиотечного обслуживания и одновременно опередило регулирование правового сегмента по интеллектуальной собственности. Авторы представили краткий обзор более 20 публикаций известных специалистов в области библиотечного дела и права; осветили сложности, возникавшие в период 2000-2014 гг. при обслуживании пользователей библиотек России. Приведены ссылки на законодательные акты, которыми следует руководствоваться, начиная с 2014 года.

Благодаря правовым нормам, изложенным в Федеральном законе в № 35-ФЗ [8], библиотекам страны сегодня удается легитимно выполнять заказы пользователей по технологии ЭДД.

Национальная электронная библиотека. 17 сентября 2015 г. Правительство РФ внесло в Государственную Думу РФ законопроект о создании государственной информационной системы (ГИС) «Национальная электронная библиотека» (НЭБ) [11], нацеленный на формирование единого электронного собрания полных текстов научных, образовательных, культурных ресурсов и обеспечение свободного, равного, всеобщего доступа к оцифрованным документам на всей территории России. На заседании круглого стола «Взаимодействие НЭБ с библиотеками-участниками», который состоялся 31 мая 2016 г. в РГБ, обсуждалось наполнение контента по научно-образовательной тематике; оцифровка художественных произведений, лучших образцов детских книг, нот, нормативных, методических документов [12]. Для того чтобы ресурсы НЭБ стали полезны представителям научной среды, необходимо иметь возможность определить индекс цитирования. Технические решения по поиску, обработке информации, разграничению прав и предоставлению максимального доступа, применяемые в НЭБ, предусматривают соблюдение всех требований законодательства.

В 2016 г. вступил в силу Федеральный закон № 342-ФЗ «О внесении изменений в Федеральный закон “О библиотечном деле" в части создания федеральной государственной информационной системы “Национальная электронная библиотека" " [13]. В законе «О библиотечном деле» появилась новая статья «18.1. Национальная электронная библиотека», в которой названы участники НЭБ (государственные, муниципальные, образовательные, научные библиотеки и др.), обеспечивающие хранение книжных памятников и федерального электронного ОЭ документов, прописаны возможности доступа реальным, виртуальным пользователям, физическим лицам, осуществляющим доступ к НЭБ в библиотеках и через Интернет [14].

Статья «19. Участие государства в обеспечении координации и кооперации библиотечного обслуживания» закона «О библиотечном деле» гласит, что государству отводится роль по стимулированию и созданию условий для взаимоиспользования библиотечных ресурсов (межбиб- 
лиотечный абонемент, сводные каталоги, автоматизированные базы данных (БД), депозитарии) [14]. Итак, можно надеяться, что сообщество библиотек России найдет правильное решение о доступе к объектам НЭБ в процессе обслуживания по МБА и ДД коллективов (организаций, предприятий, учреждений).

\section{Технологические подходы с применением автоматизации и информатизации}

В настоящее время в России и за рубежом системы МБА и ДД многих библиотек используют автоматизированные режимы работы [15; 16]. С появлением ОЭ электронной копии печатного издания и функционированием НЭБ в России обязательно возникнут вопросы использования оцифрованных изданий по МБА и ДД. Неизбежно придется выстраивать пути взаимодействия всех библиотек с НЭБ, чтобы полноценно обслуживать коллективных и индивидуальных пользователей, определить привилегии библиотекам - участницам НЭБ в выполнении заказов, вести интегрированный поиск библиотекам-участницам по ресурсам.

К 2020 г. многие издатели прогнозировали рост выпуска большинства изданий только в цифровом формате, включая научные. В этом случае предстоит решать новую проблему в информационном секторе России, в том числе по МБА и ДД. Поскольку мировой тенденцией является интеграция служб МБА и ДД на основе существующих автоматизированных систем (AC), то в России обращаются к опыту библиотек Великобритании [17], Италии [18], балканских стран [19].

Доступ к электронным ресурсам в фондах библиотек открывают многие зарубежные коллеги. Например, в Норвегии к оцифрованным книгам, опубликованным до 2000 г., пользователи имеют свободный доступ. Студентам, сотрудникам университетов и колледжей доступны материалы, защищенные авторским правом. Как показал анализ, данная услуга не нанесла вреда издателям, поскольку правообладатели ежегодно получают вознаграждение в зависимости от количества страниц, просмотренных в библиотеках. Британская библиотека практикует с 2013 г. использование электронного ОЭ [20, с. 43].

\section{Организационно-технологические вопросы}

Реглалентирующие докуленты. РГБ в течение многих лет является головным центром Национальной системы МБА и ДД РФ. До начала 2000-х гг. в ссрере МБА действовал ГОСТ 7.31-89 «Единая государственная система межбиблиотечного абонемента», который регламентировал единообразие в организации обслуживания пользователей, в 2003 г. появились: «Положе- ние о национальной системе межбиблиотечного абонемента и доставки документов Российской Федерации» [21] и «Порядок функционирования национальной системы межбиблиотечного абонемента и доставки документов Российской Федерации» [22]. Указанные документы являются основополагающими при выдаче и получении документов на межбиблиотечном уровне, но они требуют корректировки, чтобы актуализировать ряд изменений в оказании услуг, которые появились после 2003 года.

В 2014 г. секция МБА и ДД Российской библиотечной ассоциации (РБА) инициировала пересмотр «Положения...». Поступившие от коллег предложения обсуждались на РБА в 2016 г. [23], в дальнейшем предстоит придать документу официальный статус в целостной системе МБА и ДД России.

Возможно, следует разработать новый ГОСТ, чтобы аккумулировать ценный опыт, накопленный ранее, и отразить развивающиеся технологии последнего 20-летия в функционировании ДД, МБА, ЭДД в современных реалиях.

Оперативность выполнения заказов. Как показал анализ сроков выполнения заказов МБА и ДД, в ряде случаев и по многим причинам ответы доходят до пользователей через длительные промежутки времени. Например, читатели ГПНТБ СО РАН в 2013-2015 гг. получили от информационно-библиотечных организаций России электронные копии, срок доставки которых длился три дня (в 2013 г. - 69\%, 2014 г. $52 \%, 2015$ г. - 33\% ). За три года в среднем $48 \%$ цифровых копий доставлялись в Новосибирск долго, несмотря на электронные возможности. Как известно, для доставки электронных копий внутри страны и из-за рубежа нет технических и экономических ограничений, используя $\mathrm{AC}$, заказы можно выполнять очень быстро. Например, Центр доставки документов Британской библиотеки (British Library Document Supply Centre, BLDC) уже в 1996 г. обеспечивал ЭДД конечному пользователю в течение двух часов [24]. Способствуют оперативности выполнения заказов по МБА и ДД различные объединения: Онлайновый компьютерный библиотечный центр (Online Computer Library Center, OCLC) в CША; Международная система ДД между государствами бассейна Северного моря, координатор Nordinfo; Консорциум SUBITO (итал. - быстро, скоро), объединивший научные библиотеки Германии, Австрии и Швейцарии.

Благодаря интеграции ресурсов зарубежных библиотек через SUBITO за один сеанс осуществляется поиск по широкому тематическому профилю и заказ документов у любого члена Консорциума. Копии статей, глав, разделов из документов доставляются в подразделение международного межбиблиотечного абонемента (ММБА) Государственной публичной научно-технической 
библиотеки (ГПНТБ) России электронным путем или в бумажном виде (в случае лицензионных документов). Заказчику копии передаются максимально оперативно по электронной почте, факсу, с помощью «Почты России». Доля отказов от SUBITO низкая [25].

Как правило, крупные российские библиотеки сотрудничают по линии ММБА и ДД с мировыми информационными центрами (BLDSC, OCLC, SUBITO и др.), используя для взаимодействия имеющиеся АС. В дальнейшем следует прибегнуть к международным стандартам для проектирования, разработки и эксплуатации АС МБА и ДД, что позволит быстрее оказывать коммуникационную поддержку российским ученым.

В течение нескольких лет в ГПНТБ СО РАН проводится изучение международного стандарта ISO 18626 Interlibrary Loan Transactions [26] c целью его применения в обновляемой АС МБА и ДД [27]. В стандарте приведены шесть режимов обслуживания: Express (курьерский, специальный, срочный); Normal (обычный); Rush (быстрая доставка); SecondaryMail (вспомогательный почтовый); Standard (стандартный); Urgent (экстренный). К сожалению, в России такого разнообразия видов ДД нет. Несмотря на это, исходя из российских реалий и учитывая значительную территориальную протяженность страны, по аналогии с коммерческими службами доставки библиотеки могут предлагать ускоренные, обычные, к определенному времени виды доставки. Время выполнения доставки можно варьировать от нескольких часов до двух дней для ЭДД и до 10 дней для оригиналов и копий.

Помимо этого необходимо осуществлять контроль оперативности отработки заказов, вырабатывать предупредительные меры, направленные на устранение их превышения.

Предотвращение отказов. Высоко оценить качество услуг в системе МБА и ДД РФ не позволяет наличие отказов. Так, за 2013-2015 гг. читатели ГПНТБ СО РАН получили 12,$3 ; 22 ; 27,8 \%$ отказов соответственно. Большинство отказов имеют формулировку «нет в библиотеке» (причем это относится к отечественным изданиям). Первая причина заключается в том, что издающие организации допускают нарушения закона [5], не отправляя издания в РКП. Другая причина связана со списанием изданий из фондов библиотек. Об этих проблемах также писали коллеги из БЕН РАН $[4$, c.16]. К сожалению, отказы характеризуют неготовность библиотек к полноте обслуживания и порождают недовольство читателей.

В соответствии с законом «О библиотечном деле» библиотеки не имеют права отказывать пользователям МБА и ДД в получении документов, которые приобретены за счет государственных средств и находятся в открытых фондах [14]. Чтобы не нарушать права граждан на получение информации, службы МБА и ДД обязаны выпол- нять заказы с минимальными ограничениями. Если нет возможности выдать оригинал, то копии можно выслать, обеспечивая сохранность документа и соблюдая авторские права. Оперативность доставки документов также диктует необходимость возобновления процесса перенаправления отказов от одного исполнителя к другому по причине «единственный экземпляр не выдается по МБА». Как показывает практика, каждая библиотека имеет свой набор формулировок отказов. В целях оперативности и удобства применения $\mathrm{AC}$ следовало бы разработать унифицированный перечень стандартных причин.

Оптилизация платных услуг. Согласно Федеральному закону № 83-ФЗ «О внесении изменений в отдельные законодательные акты Российской Федерации в связи с совершенствованием правового положения государственных (муниципальных) учреждений» все библиотеки планируют государственное задание [28]. Одновременно с этим по-прежнему остается право на оказание платных услуг. Но иногда вызывают удивление высокие цены, которые устанавливают библиотеки, тем самым удерживая читателей от оформления заказов или вынуждая аннулировать уже отправленные. Так произошло в $36,5 \%$ случаях, когда в 2015 г. читатели ГПНТБ СО РАН отказались получать документы от других организаций по причине того, что не устраивает цена или срок доставки.

Существуют мнения, что неоправданным следует считать взимание платы за отказы, практикуемое отдельными библиотеками. Не доставив документ, читателя заставляют платить за пробелы в комплектовании или нарушение библиотечной технологии. Устанавливая новые тарифы, следует иметь ввиду, что рост цен препятствует получению необходимой информации читателями и не увеличивает производственные показатели служб МБА и ДД.

Сбор и доступность статистических показателей работы. Известно, что для статистического учета показателей многие библиотеки России используют различные рекомендуемые формы. Например, форму 6-НК применяют в библиотеках Министерства культуры Российской Федерации. Для МБА и ДД в ней имеется одна колонка «выдано (просмотрено) документов из фондов других библиотек, в том числе полученных по МБА и ММБА». В нее пишут часть показателей, а остальные данные (пользователи, выдано из фонда, копирование, сканирование, отказы) плюсуют к общим цифрам по библиотеке.

Библиотеки РАН заполняют форму, разработанную Информационно-библиотечным советом РАН. Учитываются следующие показатели: абоненты МБА и ДД, ММБА; заказы по требованиям читателей, абонентов, в том числе по ММБА; выдача документов по МБА и ДД, в том числе средствами ЭДД; выдача документов по ММБА, 
в том числе средствами ЭДД; выдача документов из удаленных полнотекстовых библиотек и БД.

РГБ несколько лет занимается приведением к единообразию показателей МБА и ДД, рассылая по библиотекам формы для заполнения. Собранные данные выставляются на сайте РБА в разделе «Секция МБА и ДД», что следует признать положительным шагом. Однако не все библиотеки отправляют показатели, например, в перечне нет названий вузовских и отраслевых библиотек России. В библиотечных публикациях не встречаются данные о деятельности МБА и ДД по всей стране, что не позволяет увидеть полную картину объемов оказываемых услуг и вести сравнительный анализ. Более того, показатели МБА и ДД не представлены в региональных и федеральных сборниках статистики.

Таким образом, рассмотренные компоненты развития МБА и ДД представляют собой ряд общесистемных задач с одновременным встраиванием в интегрированную информационную систему национального масштаба. В каждой компоненте выявлены недостатки и предложены направления движения. Если российское библиотечное сообщество примет действенные решения, они послужат совершенствованию МБА и ДД. В результате выиграют пользователи, которые получат более оперативный доступ к научно-технической информации, образовательным, культурным и иным ресурсам, что будет способствовать расширению коммуникационной среды.

\section{Список источников}

1. Цукерблат Д.М., Красильникова И.Ю. Информационные технологии и межбиблиотечный абонемент // Библиотековедение. 2001. № 4. С. 48-54.

2. Красильникова И.Ю. Стратегия развития: инновации в деятельности межбиблиотечного абонемента и доставки документов / Библиотечное дело. 2013. № 13 (199). С. 11-14.

3. Подкорытова Н.И. Издание научных книг в России и тенденции их распространения в академических библиотеках // Новые электронные технологии в информационном обслуживании ученых и специалистов Сибирского отделения Российской академии наук. Новосибирск, 2014. С. 13-16.

4. Колерова Т.С. Служба межбиблиотечного абонемента Библиотеки по естественным наукам РАН и комплектование ее фонда / / Научные и технические библиотеки. 2016. № 3. С. 12-18.

5. Федеральный закон от 29.12.1994 № 77-ФЗ (ред. от 03.07.2016) «Об обязательном экземпляре документов» [Электронный ресурс] // Законы, кодексы и нормативно-правовые акты Российской Федерации. URL: http://legalacts.ru/doc/federalnyi-zakon-ot29121994-n-77-fz-s/(дата обращения: 19.07.2017).

6. Обязательный экземпляр: вопросов больше, чем ответов // Университетская книга. 2014. № 9 (ноябрь). C. $22-27$.

7. Эйдемиллер И.В. Продолжается обсуждение поправок в закон «Об обязательном экземпляре до- кументов» [Электронный ресурс] // Российская библиотечная ассоциация. 2016, 9 марта. URL: http://www.rba.ru/content/news/vid_news_str. php?id=5259 (дата обращения: 19.07.2017).

8. Федеральный закон Российской Федерации от 12.03.2014 г. № 35-Ф3 «О внесении изменений в части первую, вторую и четвертую Гражданского кодекса Российской Федерации и отдельные законодательные акты Российской Федерации» // Собрание законодательства РФ. 2014. № 11. Ст. 1100. С. 2740-2741.

9. Евтушенко Н.В., Красильникова И.Ю. Соблюдение авторских прав в деятельности межбиблиотечного абонемента и доставки документов / Вестник Новосибирского государственного университета. Серия Право. 2015. Т. 11, № 2. С. 136-147.

10. Евтушенко Н.В., Красильникова И.Ю. Авторское право и МБА / / Независимый библиотечный адвокат. 2015. № 3 (93). С. 43-50.

11. Сахаров Н.А. Законодательная основа для Национальной электронной библиотеки // Библиотековедение. 2015. № 6. С. 19-22.

12. 31 мая в Российской государственной библиотеке в рамках Дня открытых дверей прошел круглый стол «Взаимодействие НЭБ с библиотеками-участниками» [Электронный ресурс] // Национальная электронная библиотека. URL: https://xn--90ax2c.xn--p1ai/news/ details.php?ID=3398 (дата обращения: 19.07.2017).

13. Федеральный закон от 3 июля 2016 г. № 342-ФЗ «О внесении изменений в Федеральный закон “О библиотечном деле” в части создания федеральной государственной информационной системы “Национальная электронная библиотека" " [Электронный ресурс] // Российская газета. 2016. 8 июля. URL: https://rg.ru/2016/07/08/elbibl-dok. html (дата обращения: 19.07.2017).

14. Федеральный закон от 29.12.1994 № 78-ФЗ (ред. от 03.07.2016) «О библиотечном деле» (с изм. и доп., вступ. в силу с 03.10.2016) [Электронный ресурс] // Законы, кодексы и нормативно-правовые акты Российской Федерации. URL: http://legalacts.ru/doc/ federalnyi-zakon-ot-29121994-n-78-fz-о/ (дата обращения: 19.07.2017).

15. Власова C.A. Интегрированная система межбиблиотечного абонемента в Библиотеке по естественным наукам РАН / Библиотеки национальных академий наук: проблемы функционирования, тенденции развития : науч.-практ. и теорет. сб. Киев, 2006. Вып. 4. C. $244-256$.

16. Баженов C.Р., Паршиков Р.М. Разработка автоматизированного рабочего места сотрудника МБА под ИРБИС // Библиосфера. 2009. № 2. С. 53-57.

17. Appleyard A. British Library Document Supply: an Information Service Fit for the Future // Interlending \& Document Supply. 2015. Vol. 43, № 1. P. 9-13.

18. Mangiaracina $\mathrm{S}$. Assessing the Effectiveness of a National Resource Sharing System / / Interlending \& Document Supply. 2014. Vol. 42, № 2/3. P. 98-104.

19. Vehovec R., Lešnik B. The Implementation of ILL in COBISS [Электронный pecypc] // Universal Availability of Publications Core Activity 7th Interlending and Document Supply International Conference. URL: https://web.archive.org/web/20070713061858/ http://www.ifla.org/VI/2/conf/vehovec.pdf (дата обращения: 24.08.2017). 
20. Библиотеки, граждане, общества: вместек знаниям // Университетская книга. 2014. № 9. С. 40-45.

21. Положение о национальной системе межбиблиотечного абонемента и доставки документов Российской Федерации [Электронный ресурс] // Российская государственная библиотека. URL: http://udo.rsl. $\mathrm{ru} /$ upload/doc/Polojenie_MBA.pdf (дата обращения: 19.07.2017).

22. Порядок функционирования национальной системы межбиблиотечного абонемента и доставки документов Российской Федерации. Москва, 2003. $19 \mathrm{c.}$

23. Гурбанова О.Н. Проблемы прежние: к редактированию «Положения о национальной системе межбиблиотечного абонемента и доставки документов Российской Федерации» // Информационный бюллетень РБА. 2017. № 79. С. 20-25.

24. Лаврик О.Л., Глухов В.А. Организация электронной доставки документов в библиотеке : конспект лекции для курса «Интернет в библиотеке». Новосибирск, 2000. С. 18.
25. Середа O.A. Международная деятельность ГПНТБ России в области МБА и доставки документов // Библиотечное обслуживание в информационном веке. Москва : ГПНТБ России, 2009. С. 51-60.

26. ISO 18626 Interlibrary Loan Transactions. Open Codes [Электронный ресурс]. URL: http://illtransactions. org/opencode/ (дата обращения: 19.07.2017).

27. Баженов С.Р., Красильникова И.Ю., Паршиков Р.М. Международные стандарты, регламентирующие форматы электронных сообщений при обслуживании по межбиблиотечному абонементу: история и современное состояние // Научные и технические библиотеки. 2017. № 2. С. 31-41.

28. Федеральный закон от 8 мая 2010 г. № 83-ФЗ «О внесении изменений в отдельные законодательные акты Российской Федерации в связи с совершенствованием правового положения государственных (муниципальных) учреждений» [Электронный peсурс] // Российская газета. 2010. 12 мая. URL: https://rg.ru/2010/05/12/pravovoe-izmenenie-dok. html (дата обращения: 19.07.2017).

\title{
The Development Components of the National System of Interlibrary Loan and Document Delivery in Support of Scientific Communications in Russia
}

\author{
Irina Y. Krasilnikova, \\ State Public Scientific Technological Library of the Siberian Branch of the Russian Academy of Sciences \\ (SPSTL SB RAS), 15 Voskhod Str., Novosibirsk, 630200, Russia \\ E-mail: krasilnikova@spsl.nsc.ru
}

\begin{abstract}
In the modern conditions of expansion of digital environment in the process of Interlibrary Loan (ILL) and Document Delivery (DD) services, there arise a number of problems, on successful solution of which will depend the development of sharing the library-information resources, promoting scientific communications. To determine the benchmarks of progression of ILL and DD there are identified the components that can enhance the activities. These include: completeness of acquisition; updating of legislative documents; technological approaches with the use of automation and informatization; organizational and technological issues (regulatory documents, efficient execution of orders, prevention of refusals, optimization of the fee-based services and the availability of statistical indicators of work).

There are considered the main ways to facilitate adaptation of ILL and DD departments to the emerging conditions of the electronic environment and the subsequent update. Attention is drawn to the need of establishing interaction between the ILL and DD departments with the National Electronic Library, compliance with the legal norms in the process of digitization of documents and the accessibility of electronic documents to the users of ILL and DD. It is proposed to develop a new State Standard on ILL and DD, to secure uniform normative periods of order processing, to control the efficiency of their performance and to develop preventive actions to eliminate delays. The efficiency of DD necessitates the creation of a unified list of the refusal formulation, the relaunching of the procedure of redirecting the refusals due to the reason: "A single copy cannot be used for ILL" from one contractor to another. Fees for refusals should be recognized unjustified, because the customer has not received the required document. The collection and availability of the statistical indicators of ILL and DD activities will allow obtaining and studying the quantita-
\end{abstract}


tive and qualitative characteristics of the activity. The proposed actions are targeted at the optimization of ILL and DD in the Russian Federation.

Key words: Automation, Copyright Law, Document Delivery, Acquisition, Interlibrary Loan, ILL, Legal Deposit, Efficiency, Fee-based Services, Regulatory Documentation, Standards, Statistical Indicators, Digital Library.

Citation: Krasilnikova I.Y. The Development Components of the National System of Interlibrary Loan and Document Delivery in Support of Scientific Communications in Russia, Bibliotekovedenie [Library and Information Science], 2017, vol. 66, no. 4, pp. 387-395. DOI: 10.25281/0869-608X-2017-66-4-387-395.

\section{References}

1. Tsukerblat D.M., Krasilnikova I.Yu. Informatsionnye tekhnologii i mezhbibliotechnyi abonement [Information Technologies and Interlibrary Loan], Bibliotekovedenie [Library and Information Science], 2001, no. 4, pp. $48-54$.

2. Krasilnikova I.Yu. Strategiya razvitiya: innovatsii v deyatel'nosti mezhbibliotechnogo abonementa i dostavki dokumentov [Development Strategy: Innovations in the Work of Interlibrary Loan and Document Delivery], Bibliotechnoe delo [Librarianship], 2013, no. 13 (199), pp. 11-14.

3. Podkorytova N.I. Izdanie nauchnykh knig v Rossii i tendentsii ikh rasprostraneniya $\mathrm{v}$ akademicheskikh bibliotekakh [Publishing of Scientific Books in Russia and the Trends of their Distribution in Academic Libraries], Novye elektronnye tekhnologii $v$ informatsionnom obsluzhivanii uchenykh i spetsialistov Sibirskogo otdeleniya Rossiiskoi akademii nauk [New Electronic Technologies in the Information Service of Scientists and Specialists of the Siberian Branch of the Russian Academy of Sciences]. Novosibirsk, 2014, pp. $13-16$.

4. Kolerova T.S. Sluzhba mezhbibliotechnogo abonementa Biblioteki po estestvennym naukam RAN i komplektovanie ee fonda [The RAS Library for Natural Sciences ILL Service and Collection Development], Nauchnye i tekhnicheskie biblioteki [Scientific and Technical Libraries], 2016, no. 3, pp. 12-18.

5. Federal'nyi zakon ot 29.12.1994 № 77-FZ “Ob obyazatel'nom ekzemplyare dokumentov" [Federal Law of December 29, 1994, No. 77-FZ “On Legal Deposit Copy of Documents"], Internet-biblioteka "Normativnaya dokumentatsiya" ["Normative Documentation" Internet Library]. Available at: http:// libnorm.ru/Data2/1/4293755/4293755799.htm (accessed 19.07.2017).

6. Obyazatel'nyi ekzemplyar: voprosov bol'she, chem otvetov [Legal Deposit: There Are More Questions than Answers], Universitetskaya kniga [University Book], 2014, no. 9, pp. 22-27.

7. Eidemiller I.V. Prodolzhaetsya obsuzhdenie popravok v zakon "Ob obyazatel'nom ekzemplyare dokumentov" [The Discussion of the Amendments to the Law "On Legal Deposit Copy of Documents" Continues], Rossiiskaya bibliotechnaya assotsiatsiya [Russian Library Association]. Available at: http://www.rba.ru/ content/news/vid_news_str.php?id=5259 (accessed 19.07.2017).

8. Federal'nyi zakon Rossiiskoi Federatsii ot 12.03.2014 g. № 35-FZ “O vnesenii izmenenii v chasti pervuyu, vtoruyu i chetvertuyu Grazhdan- skogo kodeksa Rossiiskoi Federatsii i otdel'nye zakonodatel'nye akty Rossiiskoi Federatsii" [Federal Law of the Russian Federation of 12.03.2014 № 35FZ "On Amendments to Parts One, Two and Four of the Civil Code of the Russian Federation and Certain Legislative Acts of the Russian Federation"], Sobranie zakonodatel'stva RF [Legislation Collection of the Russian Federation], 2014, no. 11, article 1100, pp. $2740-2741$.

9. Evtushenko N.V., Krasilnikova I.Yu. Soblyudenie avtorskikh prav v deyatel'nosti mezhbibliotechnogo abonementa i dostavki dokumentov [Copyright Compliance in the Work of Interlibrary Loan and Document Delivery], Vestnik Novosibirskogo gosudarstvennogo universiteta. Seriya Pravo [Bulletin of the Novosibirsk State University. Law Series], 2015, vol. 11, no. 2, pp. $136-147$.

10. Evtushenko N.V., Krasilnikova I.Yu. Avtorskoe pravo i MBA [Copyright and Interlibrary Loan], Nezavisimyi bibliotechnyi advokat [Independent Library Lawyer], 2015, no. 3 (93), pp. 43-50.

11. Sakharov N.A. Zakonodatel'naya osnova dlya Natsional'noi elektronnoi biblioteki [The Legislative Basis of the National Electronic Library], Bibliotekovedenie [Library and Information Science], 2015, no. 6 , pp. $19-22$.

12. 31 maya v Rossiiskoi gosudarstvennoi biblioteke v ramkakh Dnya otkrytykh dverei proshel kruglyi stol "Vzaimodeistvie NEB s bibliotekami-uchastnikami" [On May 31, at the Russian State Library, within the Framework of the Open Day, There Was a Round Table "Interaction of the National Electronic Library with its Libraries-Participants"], Natsional'naya elektronnaya biblioteka [National Electronic Library]. Available at: https://xn--90ax2c.xn--p1ai/news/details. php?ID=3398 (accessed 19.07.2017).

13. Federal'nyi zakon ot 3 iyulya 2016 g. № $342-\mathrm{FZ}$ “O vnesenii izmenenii v Federal'nyi zakon "O bibliotechnom dele" $v$ chasti sozdaniya federal'noi gosudarstvennoi informatsionnoi sistemy "Natsional'naya elektronnaya biblioteka"' [Federal Law of July 3, 2016, № 342-FZ “On Amendments to the Federal Law "On Librarianship" to Create the Federal State Information System "National Electronic Library"”], Rossiiskaya gazeta [Russian Gazette], July 8, 2016. Available at: https://rg.ru/2016/07/08/elbibl-dok. html (accessed 19.07.2017).

14. Federal'nyi zakon ot 29.12.1994 № 78-FZ (red. ot 03.07.2016) "O bibliotechnom dele" (s izm. i dop., vstup. v silu s 03.10.2016) [Federal Law of 29.12.1994 № 78-FZ (edition of 03.07.2016) “On Librarianship” 
(with the amendments and additions that took effect on 03.10.2016)], Zakony, kodeksy i normativno-pravovye akty $v$ Rossiiskoi Federatsii [Laws, Codes and Legal Acts in the Russian Federation]. Available at: http:// legalacts.ru/doc/federalnyi-zakon-ot-29121994-n78-fz-o/ (accessed 19.07.2017).

15. Vlasova S.A. Integrirovannaya sistema mezhbibliotechnogo abonementa $\mathrm{v}$ Biblioteke po estestvennym naukam RAN [The Integrated System of Interlibrary Loan in the Library for Natural Sciences of the Russian Academy of Sciences], Biblioteki natsional'nykh akademii nauk: problemy funktsionirovaniya, tendentsii razvitiya: nauch.-prakt. i teoret. sb. [The Libraries of National Academies of Sciences: Problems of Functioning, Trends of Development: scientificpractical and theoretical collection]. Kiev, 2006, issue 4 , pp. 244-256.

16. Bazhenov S.R., Parshikov R.M. Razrabotka avtomatizirovannogo rabochego mesta sotrudnika MBA pod IRBIS [Developing the ILL Specialist's Automated Workplace for the IRBIS], Bibliosfera [Bibliosphere], 2009, no. 2, pp. 53-57.

17. Appleyard A. British Library Document Supply: an Information Service Fit for the Future, Interlending \& Document Supply, 2015, vol. 43, no. 1, pp. 9-13.

18. Mangiaracina S. Assessing the Effectiveness of a National Resource Sharing System, Interlending \& Document Supply, 2014, vol. 42, no. 2/3, pp. 98-104.

19. Vehovec R., Lešnik B. The Implementation of ILL in COBISS, Universal Availability of Publications Core Activity 7th Interlending and Document Supply International Conference. Available at: https://web. archive.org/web/20070713061858/http:/www.ifla. org/VI/2/conf/vehovec.pdf (accessed 19.07.2017).

20. Biblioteki, grazhdane, obshchestva: vmeste k znaniyam [Libraries, Citizens, Societies: Together to the Knowledge], Universitetskaya kniga [University Book], 2014, no. 9, pp. 40-45.

21. Polozhenie o natsional'noi sisteme mezhbibliotechnogo abonementa i dostavki dokumentov Rossiiskoi Federatsii [Regulations on the National System of Interlibrary Loan and Document Delivery of the Russian Federation], Rossiiskaya gosudarstvennaya biblioteka [Russian State Library]. Available at: http:// udo.rsl.ru/upload/doc/Polojenie_MBA.pdf (accessed 19.07.2017).

22. Poryadok funktsionirovaniya natsional'noi sistemy mezhbibliotechnogo abonementa i dostavki dokumen- tov Rossiiskoi Federatsii [Functioning of the National System of Interlibrary Loan and Document Delivery of the Russian Federation]. Moscow, 2003, 19 p.

23. Gurbanova O.N. Problemy prezhnie: k redaktirovaniyu "Polozheniya o natsional'noi sisteme mezhbibliotechnogo abonementa i dostavki dokumentov Rossiiskoi Federatsii" [The Old Problems: Editing the "Regulations on the National System of Interlibrary Loan and Document Delivery of the Russian Federation"], Informatsionnyi byulleten' RBA [RLA Information Bulletin], 2017, no. 79, pp. 20-25.

24. Lavrik O.L., Glukhov V.A. Organizatsiya elektronnoi dostavki dokumentov $v$ biblioteke: konspekt lektsii dlya kursa "Internet $v$ biblioteke" [Organizing the Electronic Document Delivery in the Library: Lecture Notes for the Course "Internet in the Library"]. Novosibirsk, 2000, p. 18.

25. Sereda O.A. Mezhdunarodnaya deyatel'nost' GPNTB Rossii v oblasti MBA i dostavki dokumentov [International Activities of the Russian National Public Library for Science and Technology in ILL and Document Delivery], Bibliotechnoe obsluzhivanie v informatsionnom veke [Library Service in the Information Age]. Moscow, GPNTB Rossii Publ., 2009, pp. 51-60.

26. ISO 18626 Interlibrary Loan Transactions. Open Codes. Available at: http://illtransactions.org/opencode/ (accessed 19.07.2017).

27. Bazhenov S.R., Krasilnikova I.Yu., Parshikov R.M. Mezhdunarodnye standarty, reglamentiruyushchie formaty elektronnykh soobshchenii pri obsluzhivanii po mezhbibliotechnomu abonementu: istoriya i sovremennoe sostoyanie [International Standards to Regulate Formats of Electronic Messages for ILL Services: History and Current Status], Nauchnye i tekhnicheskie biblioteki [Scientific and Technical Libraries], 2017, no. 2, pp. 31-41.

28. Federal’nyi zakon ot 8 maya 2010 g. № $83-\mathrm{FZ}$ “O vnesenii izmenenii v otdel'nye zakonodatel'nye akty Rossiiskoi Federatsii v svyazi s sovershenstvovaniem pravovogo polozheniya gosudarstvennykh (munitsipal'nykh) uchrezhdenii" [Federal Law of May 8, 2010, № 83-FZ “On Amendments to Certain Legislative Acts of the Russian Federation in Connection with the Improvement of Legal Status of State (Municipal) Institutions"], Rossiiskaya gazeta [Russian Gazette], May 12, 2010. Available at: https:// rg.ru/2010/05/12/pravovoe-izmenenie-dok.html (accessed 19.07.2017). 